\title{
SEN policies and migrant children in Italian schools: micro-exclusions through discourses of equality
}

\author{
Valentina Migliarini $^{* a}$, Simona D'Alessio $^{b}$, and Fabio Bocci ${ }^{c}$ \\ ${ }^{a}$ University of Bologna, Education Department, Italy; ${ }^{b}$ Knowledge and Human \\ Development Authority, Dubai; ${ }^{c}$ Universita degli Studi di Roma Tre, Scienze della \\ Formazione, Rome, Italy
}

\begin{abstract}
This article analyses the underpinnings and implementation of Special Educational Needs (SEN) policies in Italy, within the internationally celebrated policy arena of Integrazione Scolastica (i.e., school integration), through an equity prism. The aim is to explore the extent to which SEN policies in Italy foster inclusion and equity in education, particularly when targeting migrant children. In doing so, the paper intends to advance critical thinking about the recent phenomenon of overrepresentation, or 'SENitization', of students from migrant backgrounds within the SEN macro-category in Italy, by examining policy narratives both nationally and locally. Analysing the policies through the intersectional lens of Disability Critical Race Theory in education framework, this article suggest that Italian SEN policies legitimates forms of micro-exclusions of migrant students in mainstream classrooms, despite discursive promises of equality for all students.
\end{abstract}

Keywords: SEN policies; inclusive education; DisCrit; migrant students; Italy

\section{Introduction}

This paper explores the foundations and contrapuntal logic of Special Educational Needs (SEN) policies ${ }^{1}$ introduced by the Italian Ministry of Public Education (Ministero dell'Istruzione dell'Università e della Ricerca MIUR) in 2012. These policies have been adopted 40 years after the passing of the internationally celebrated policy of Integrazione Scolastica ${ }^{2}$ (i.e., school integration), which envisaged the participation of all pupils, with or without disabilities, in the process of learning. Though the special education paradigm has permeated the making of Integrazione Scolastica (D'Alessio, 2011), the creation of the macro-category of Special Educational Needs (or Bisogni Educativi Speciali) is a new phenomenon; it aligns Italy with the rest of Europe, wherein SEN existed since the end of the1970s (D'Alessio, 2014). As in most 'western' countries, Italian SEN policies have been implemented to extend rights and entitlements for all those learners experiencing school failure which could not be provided with support under existing disability laws (Artiles, 2013). In this paper, we argue that it is not a coincidence that SEN policies

\footnotetext{
* Corresponding author's email: valentina.migliarin2@unibo.it
} 
have been introduced at a time when an increasing number of migrant and forced migrant children is populating Italian schools (see Ministero del Lavoro, 2015; Programma Integra, 2013).

The nexus of special education and migration, resulting in disproportionality, is an under-debated topic in Italian literature, and very little or no reference is made about Italy in much of European and international comparative research on the subject (e.g., Berhanu \& Dyson, 2012; European Union, 2012; Gabel et al., 2009; Wiley et al., 2013). We use Tomlinson's (2017) sociological perspective on social, political and economic policies and practices that comprises special and inclusive education. Particularly we emphasize Tomlinson's argument affirming that under global neoliberal reforms in education, special education has been increasingly characterised by a 'punitive and paternalistic benevolence', leading to a conditional inclusion of perceived 'defective' subjects into an unequal society at lower levels (Tomlinson, 2017 , p. 4). Drawing on studies that have critically explored disproportionality in special education of marginalised groups at the international level (Annamma, 2018; Artiles et al., 2005; Brantlinger, 2008; Erevelles \& Minear, 2010; Harry \& Klingner, 2014; Kivirauma et al., 2006; Reid \& Knight, 2006), this paper sheds light on the recent Italian phenomenon of over-representation of (forced) migrant children in the SEN category, or 'SENitization' (Migliarini, 2018). Importantly, it explores how SEN policies have catalysed processes of 'SENitization' and micro-exclusions (Migliarini, 2014) of migrant students.

This paper is the result of our collective struggle to combine the research agenda on migrant education and on disability studies in the Italian context, distancing ourselves from existing research on the issue that is steeped in color-evasion and silence on interlocking systems of oppression (Caldin, 2012). For this purpose, we interrogate the underpinnings, tensions, and discrepancies of Italian SEN policies through the intersectional and interdisciplinary framework of Disability Critical Race Theory (DisCrit). DisCrit illuminates how ability is distributed and withheld based on race through policies and practices, and recognizes interlocking oppressions faced by students at the interstices of multiple differences (Annamma, Connor, \& Ferri, 2013; 2016). The closer a student is to a desired norm (e.g., white male, cis-gender, heterosexual), the more the student is imagined as capable and less subject to labelling and discipline. A DisCrit approach to Italian SEN policies contributes to show how, in the midst of spreading democracy and equality, such policies are oriented to the identification and categorization of difference within mainstream school settings.

The article begins with an overview of the international and Italian backgrounds on special education and the issue of disproportionality of marginalised students. It will continue with an examination of the affordances of DisCrit provided to the analysis of SEN policies in Italy before a description of the methodology and the sources, which gave rise to the data used. The analysis section focuses on the Critical Discourse Analysis (CDA) (Ball, Maguire, \& Braun, 2012; Fairclough, 2010) of the data gathered for the research project. Initial results point out how SEN policies are the institutional responses that attempt to assimilate or colonize migrant students, by pathologizing differences and treating them with special education interventions (Gabel et al., 2009). SENitization processes are based on the 'misleading identification' of migrant students as individuals having special educational needs when the difficulties, they experience are systemic and structural in origin (Dyson \& Gallannaugh, 2008, p. 38). Ultimately, this paper explores the pedagogical and practical implications resulting from the implementation of SEN policies. 


\section{Special education and disproportionality in international and European contexts}

In her recent publication, Sally Tomlinson (2017) suggests that expansion of special and inclusive education cannot be understood without explaining how education systems develop and their relationship to the economy. She argues that education systems change and expand to meet the goals of those who control them and involve conflict and power struggles. In the current globalised market, education represents a commodity. Further, the consideration of what constitutes valuable knowledge is driven by the hegemonic forces of capitalism (Tomlinson, 2017). Those in the position of power can regulate the amount and kind of education offered by using a strategic 'maintenance of ignorance' directed at multiply-marginalised groups - or groups that live at the intersection of multiple oppressions - determining the amount and kind of education they will receive (Archer, 1988, p. 190, in Tomlinson, 2017).

Globalisation, or the interconnectedness and homogenisation of conditions, offers a complex set of opportunities for marginalised learners, such as the diffusion of human rights and enhanced access to schooling (Gabel et al., 2009), under the banner of 'Education for All' (UNESCO, 1994; 2003). However, globalisation presents also a number of challenges, such as displacement, cross-border migration, and the shifting of marginalise status in societies around the world. As such, globalisation disguises the very real social and economic inequalities that are not merely leftovers from the past but are products of the new developments (Drilik, 1999). Within such context, special education has become subsumed into the wider global movement of inclusive education. It has started to be considered a key response to disabilities, disadvantages, and difficulties in education, as well as crucial in understanding issues of educational equality and inequality (Gabel et al., 2009). Despite assertions of inclusivity and equality, special education policies and practices seem to be actually used worldwide to maintain hierarchical social orders by 'manufacturing the inability' of children who are 'troublesome' to existing educational systems, especially by discourses of fixed ability/disability (Tomlinson, 2017, p. 7).

Disproportionality of migrant children in special education represents both current inequities (segregation of particular student groups) and new developments (use of special education to assimilate migrant students) (Gabel et al., 2009), and it constitutes the 'material effect of globalisation' (Papastephanou, 2005, p. 534). Disproportionality of marginalised students, and particularly migrant children, in special education is of increased concern because it is precisely such children for whom this categorisation may lead to further stigmatisation and isolation (Dyson \& Kozleski, 2008). Much is known about disproportionality from decades of research and debate in the United States, where the focus has been on the over-representation and under-representation of different racial and ethnic groups (Artiles, 2011; Artiles et al., 2005; Beratan, 2008; Brantlinger, 2008; Harry \& Klingner, 2014). Most of existing research in the US highlights a disparity among Black and white students, especially boys, in relation to Intellectual Disabilities (ID, formerly known as Mental Retardation or MR) (where Black pupils are twice as likely to be diagnosed compared with white pupils) and Emotional Disturbance (e.g. Harry \& Klingner, 2014). A more recent study shows how girls of colour are increasingly suspended, pathologised (i.e., hyper-surveilled, hyper-labeled, and hyper-punished), and transformed into criminal bodies. Thus, they are pushed into the school-to-prison nexus (Annamma, 2018). 
Although we are witnessing the 'globalization of white supremacy', or the racialization of subjects on a global scale (Allen, 2002, p. 467), findings of research on disproportionality in the US cannot simply be transferred to European countries without paying attention to their different histories, demographics, cultures, and education systems. According to Berhanu and Dyson (2012), there are three main challenges to understanding disproportionality in Europe: (1) there is no definition what constitutes the European region; (2) there is no single approach to education, with different countries building on their own traditions; and (3) countries vary considerably in the statistical information they collect and the extent to which these data shed light on the question of disproportionality. However, agencies such as the European Agency for Special Needs and Inclusive Education have recently begun to collect data on the phenomena of over-representation of students from migrant backgrounds in special education. Policy documents started to be issued to monitor the disproportionate number of students from minority ethnic groups in special education institutions across Europe, which encouraged a more intersectional and interdisciplinary perspective of this issue (European Agency for the Development of Special Needs Education, 2010). The report shows how, in certain countries, there is a correlation between the high number of students who have special educational needs and the existence of special schools (e.g., Belgium Lithuania, Finland, Germany), while in other countries there is a link between the identification of SEN students and the provision of additional resources (e.g. Norway and Scotland) (European Agency for the Development of Special Needs Education, 2010). This highlights that within Europe there are differences in the certification and financial procedures, as well as different SEN policies (D'Alessio, 2014).

\section{Special educational needs policies in Italy}

Italy is internationally known as a country with a progressive policy that allowed formerly excluded minority students to be educated in mainstream settings (D'Alessio, 2011; Ferri, 2008). Integrazione Scolastica is still credited for being the only policy in the world that has led to the education of disabled learners in regular classrooms since the 1970 s, clearly anticipating some of the principles that support the policy of inclusive education today: belonging, equality and democracy (D'Alessio, 2011). While the rest of the world struggled with the policies and language of special needs education, as well as segregation in special schools, Italy was already dismantling most of its separate institutions, deeming special schools a crime against fundamental human rights (Canevaro, 2001). For many years, then, Italy has been one of the few countries in the world that had not surrendered to the adoption of the classification systems of Special Educational Needs (D'Alessio et al., 2010; 2013; D’Alessio, 2011).

With the 2012 Ministerial Directive and the 2013 Circular $^{\circ} 8$, the Italian Ministry of Education introduced the new macro-category of Special Educational Needs. The new macro-category for SEN includes three micro or sub-categories of SEN:

1. Learners with severe physical or intellectual impairments diagnosed by a local health unit and provided with an Individual Educational Plan according to the Law 104/1992; 
2. Learners with learning difficulties, such as dyslexia and dyscalculia, diagnosed by a private or public clinical centre and provided with a Personal Didactical Plan according to the Law 170/2010;

3. Learners with cultural, linguistic and socio-economic disadvantages, who are identified internally by class teachers according to the most recent SEN circulars and provided with some forms of personalised support and planning.

The official motivation of these policies is to support educational institutions in their efforts to respond to the needs of all pupils, especially those who are not covered by the 1992 Law n.104. However, this three-level categorisation clearly foresees different types of support for learners depending on the category in which they fall. While students in the first sub or micro-category of Law 104/1992 are entitled to receive extra support and funding including support teachers and special devices or aids, the second and the third micro categories are only entitled to receive individual approaches to learning. Such approaches include compensatory or dispensatory mechanisms that are meant to help the 'most vulnerable categories of students' to access the class curriculum (D'Alessio, 2014, 2018).

Disability Studies (DS) scholars in Italy have taken a critical stance towards both Integrazione Scolastica and SEN policies (D'Alessio \& Cowan, 2013; Medeghini \& Valtellina, 2006). Locating disability in the oppression of a given culture and historical period rather than in impairment per se, DS scholars in Italy are concerned with the resilience of the concept of 'norm' which dominates these policies and the consequent construction of difference (Medeghini, 2013). The DS perspective in Italy attempts to shift the focus from 'the difficulties that prevent a student from following and participating in the lesson' to 'the circumstances enabling the student, with specific individual characteristics, to participate in the lesson' (D'Alessio, 2014, p. 233). DS scholars highlight how the idea of educational homogeneity is never really challenged by Integrazione Scolastica and SEN policies, and how educational interventions are targeting individual students through compensative tools. Thus, from a DS perspective, what is missing in these policies is a systemic approach that would rethink the notion of mainstream classroom and normative teaching and learning practices.

As in the North American and British contexts, where DS has been profoundly rooted in whiteness (see Bell, 2006; Erevelles \& Minear, 2010), DS scholars in Italy have debated SEN policies and Integrazione Scolastica without explicitly focusing on the experiences of migrant and minority ethnic students in schools, who appear to be increasingly labelled as having Special Educational Needs (Migliarini, 2017, 2018). This paper responds to the dearth of intersectional data collection and analysis in the Italian context with regard to the factors affecting specific children's identification with particular types of Special Educational Needs, placements and educational outcomes. Most importantly, it illustrates the value of intersectional approaches to race and disability to understand the constitutive features of 'multiply minoritizing identities' (Erevelles \& Minear, 2010, p. 127), even in the Italian context.

\section{DisCrit in the Italian context}

An interdisciplinary framework, Disability Critical Race Theory (DisCrit) ${ }^{3}$ in Education explores how normalising processes of racism and ableism position unwanted bodies outside of the category of 'normal' in order to justify their exclusion 
and segregation in education and in society (Annamma, Connor \& Ferri, 2013; 2016;). DisCrit acknowledges how, in a system of interlocking oppressions rooted in white supremacy, multiply-marginalised groups are most aware of how those oppressions function and intertwine, as well as possible disruption (Crenshaw, 1989, in Annamma \& Morrison, 2018, p. 72). As such, DisCrit centres multiplymarginalised subjects in the analysis that seeks to dismantle racially disparate outcomes (Annamma \& Morrison, 2018).

Reading Italian SEN policies through the lens of DisCrit provides a unique opportunity to think about ways to (re)organize classrooms, moving away from 'fixing' the individual - be it the student or the teacher - and shifting toward justice. As such, DisCrit can help Italian policy makers and practitioners by drawing their attention not only to the characteristics, dispositions, attitudes, and behaviours of students and teachers, but also to the structural features of the situation in which they operate (Annamma \& Morrison, 2018; Annamma, Connor, \& Ferri, 2016).

Cultivating relationships rooted in solidarity, in which teachers understand the ways students are systemically oppressed, how those oppressions are (re)produced in classrooms, and what they can do to resist those oppressions in terms of pedagogy, curriculum, and relationship, repositions students and families as valuable members (Annamma \& Morrison, 2018). Ultimately, DisCrit can help school professionals in addressing issues of diversity in the curriculum and in contemplating how discipline may be used as a tool of punishment and exclusion, or as a tool for learning.

\section{Methodology and data sources}

The data presented in this paper were collected through a qualitative pilot study, drawing on case study methods (Eisenhardt, 1989). This research strategy has been deployed here to explore the policy discourses of both SEN national documents and school policies, and their effects on the articulation of school practitioners and principals' discourse. Because of the on-going nature of the research study, this paper focuses on the CDA of the main national education policies and circulars and 10 school development plans for inclusion (known as Piano Annuale per l'Inclusione, abbreviated as PAIs), produced as a result of national SEN policies. DisCrit and its tenets guide and inform all the components of the study, including design, framing of the questions, methods, and analysis of the data.

The national education policies on SEN, analysed here, are: Ministerial Directive on the Intervention tools for pupils with special educational needs and the territorial organisation of inclusive education (2012), and Circular $n^{\circ} 8$ dated March 6, 2013 providing operational indications to schools on how to implement Special Educational Needs policies in their everyday practice. The PAIs analysed here have been elaborated by 10 schools of different cities, situated in various geographical locations across the Italian territory (e.g. North, Central, and South Italy). All the policy documents are available online, and the PAIs were downloaded from the schools' websites.

The policy documents have been collected using a purposive sampling. Thus, only information of specific interest has been selected from relevant document sources. They have been analysed through Fairclough's (2010) model of CDA and Ball et al.'s (2012) critical policy analysis. The reason for using CDA and critical policy analysis is that they focus on power, especially institutionally reproduced power, and as such they are a powerful tool for analysing opaque and transparent structural relationships 
of dominance, discrimination, power, and control manifested in language (Ball et al., 2012; Fairclough, 2010; Van Dijk, 1993). The fragments of the policy documents, analysed here, are translated from Italian to English by the authors of the present paper. Guided by the tenets of DisCrit, critical discourse analysis of SEN policies and PAIs concentrated on four main themes:

1. The nature of the language used, especially to depict migrant learners;

2. Curricular changes in inclusive terms, promotion of an inclusive school culture;

3. The role and the nature of collaboration between professionals (in and out of school environment);

4. Engagement and participation of families in the PAI.

The main research questions that have guided our studies are: (1) How are SEN policies facilitating inclusive practice for children identified as SEN and/or from migrant backgrounds? (2) How do policy makers in the Italian context formulate discourses around inclusion, diversity, race and disability within SEN policies? (3) How are these discourses translated into the PAIs at local level? (4) What is the role of school professionals, families and members of the community in the making of PAIs?

\section{Inclusion or 'SENitization'?}

In order to disrupt dysfunctional education systems that (re)produce disproportionality, DisCrit, or 'DisCrit Classroom Ecology' (Annamma \& Morrison, 2018, p. 70), centres multiply-marginalised students, their families, and communities as valuable members of our societies. Importantly, DisCrit locates students' actions, and those of their families and communities, as strategies of resistance and mechanisms to uphold their truth(s) as authentic. Thus, a DisCrit approach to education policy and practice recognize the importance of (1) situating the work in an intersectional theoretical framing to recognize the interlocking oppression that Students of Color face; (2) braiding the components of DisCrit curriculum, DisCrit pedagogy, and DisCrit solidarity to result in an education that is rooted in expansive notions of justice; (3) animating these three with DisCrit resistance, a conceptual underpinning that runs through each of the construct (Annamma \& Morrison, 2018).

Adopting a DisCrit lens shows how the notion of inclusion presented in the policy documents under analysis appears to be constructed around the idea of individualizing teaching and learning for students labelled as SEN. Additionally, diversity in the classroom is devalued through medicalised discourse of individual deficit and 'personal tragedy' (D'Alessio, 2014). The ideas of individual deficit are particularly reinforced in the case of (forced) migrant students, who are 'othered' in the discourse through the constant use of discriminatory utterances such as 'non-Italian', or 'nonItalian citizens'. ${ }^{4}$

Both the Ministerial Directive and the Circular no. 8, dated March 6, 2013, are characterized by a highly medicalised language which is particularly evident when addressing the macro-category of Special Educational Needs, and when talking about students from migrant backgrounds. For example, page 3 of the 2012 Ministerial Directive reads terms such as 'language deficit', 'specific learning disability', 'speech and language impairment', 'nosographic codes', 'international classification of 
diseases', 'comorbidities', 'compensative tools', and importantly 'social, cultural and economic disadvantage' of students from migrant backgrounds. Most of these terms can be also found at page 2 and 3 of the 2013 Circular no. 8. The medicalised language of the policies analysed recalls the medical model of disability, whose defining characteristic is the assumption that disability is located in biological impairment within the individual, 'neglecting the reality of discrimination' (Watermeyer, 2013, p. 14). Policies and services consequently aim to fix the disabled person Crossley (1999). Driven by a "moral imperative to "healthy normalcy", (Watermeyer, 2013, p. 29), the medical model considers disabled people as different and inferior, based on the premise that justifies their exclusion and creates barriers for rights and entitlements (Crossley, 1999). As such, although the two policy documents have been elaborated to provide support to all students within mainstream classrooms, it is evident that they contribute to perpetuating the individualisation and stigmatisation of difference from a standardised school 'norm'.

Such medical language expressed by national SEN policies permeates at the local level, within schools' development plan for inclusion (PAI). 9 out of the 10 PAIs considered use a language that is focused on the personal 'deficit', and 'economic/ cultural/ social disadvantage' of migrant students. 'Handicapped' (a rather derogatory term, substituted with 'disability' back in the 1990s) is still used within Italian school policies. Migrant students are usually referred to as 'foreign', 'non-Italian citizens' and 'illiterate for the level of schooling', thus SEN labelling and individualised compensatory interventions are the only way for them to get quality public education (Ministerial Directive, 2012). It is only in the PAI number 2, elaborated in a school in Bologna, that the more appropriate terms 'students not speaking Italian' (non Italofoni) is used throughout the documents. Migrant students' previous schooling experience, knowledge and educational aspirations are not considered as valuable by Italian educators. They are immediately considered as 'different from the norm', based on the assumption that they cannot speak Italian fluently and they are not familiar with the Italian culture. This provides an empirical evidence of Annamma, Connor and Ferri's (2016) argument that ableism and racism are interconnected and collusive processes that impact greatly on the lives of students at the interstices of multiple differences.

\section{Micro-exclusions in inclusive classroom}

The introduction to the 2012 Ministerial Directive praises the Italian model of school integration, implemented since the passing of law no. 517 of 1977, which has rendered the school an inclusive rather than a selective institution. It emphasizes an approach to disability and 'difference' that should be:

Very educational, for which the identification of students with disability should not happen through the certification that its own benefits but it risks relegating them in rigid labels. As such, it is useful to consider the diagnostic model set by the International Classification Functioning (ICF), which considers the person in his/her social context. This classification model allows identifying students with SEN, regardless of exclusionary labels [...] (Ministerial Directive, 2012, p. 1)

The intention of adopting the ICF model to guarantee the inclusion of SEN students, expressed by the Directive, mirrors the epistemological shift operated by many Italian scholars in considering the macro-category of SEN not exclusively from 
the medical paradigm, but from a bio-psycho-social one (D'Alessio, 2014). The ICF model should help to define the different issues that SEN pupils have to face, which might be due to biological, body, personal or environmental problems, or difficulties in social engagement. Thus, such a model intersects the individual functioning of a person with the environment in which the subject lives.

According to Italian scholars in the field of Disability Studies in Education, the limit of such a model is that, although it takes into consideration the environment and the interactions within such environment, the starting point of the SEN identification process is still the student's body as the very origin of the problem and her/his distance from a standardized 'norm' (D'Alessio, 2014).

According to both the Ministerial Directive and the Circular, a culture of school inclusion of SEN pupils is best realised through the individualisation of teaching and learning practices, expressed already by the laws 53/2008 and 170/2010, and the consequent use of 'compensative tools':

In relation to the considerations done in relation to SEN students, it seems important to elaborate an individualised and personalised program for the students with Special Educational Needs, also through the adoption of an individualised educational plan (IEP), which can be useful for the teachers and that can document the intervention strategies for the families. [...] Schools are expected to adopt compensative tools, as established by law 170/2010. (Ministerial Directive, 2012, p. 3)

The privileged tool [for realizing school inclusion] is the individualised or personalised educational plan, which has the purpose of defining, monitoring and documenting - according to a collective and participated elaboration - the most adequate intervention strategies and the assessment criteria. (Circular no. 8, 2013, p. 2)

Schools at the local level implement individualised teaching and learning strategies for inclusion. However, there seems to be a general intention of implementing curricular and organizational changes in inclusive terms, in particular referring to assessment and achievement, all the ten schools considered adopt individualised/personalised teaching and learning strategies and compensative measures, as tools for inclusion of SEN students. For instance, PAI 1 reads 'intention to adopt assessment in line with inclusive terms' (PAI 1, p. 3), or 'permanence of compensative educational tools' (p. 4). PAI 3 states 'permanence of individualised learning and teaching practices' (p. 7). PAI 6 reads 'intention of changing curricular practices but doing individualised actions for students with disability' (p.2). PAI 7 states 'Intention of promoting changes in inclusive terms in relation to curriculum' (p.3); 'individualised curriculum and evaluation' (p. 6); 'resilience of compensative strategies' (p. 9).

Behind the façade of these arguably fair strategies for inclusion resides the concept of educational homogeneity - never critically challenged at national and local levels - and the traditional ways of teaching that focus on individual pupil and his/her capacity to achieve the school standards.

\section{Delegating inclusion to support teachers}

The 2012 Ministerial Directive affirms that a culture of inclusion in schools should be fostered also through the competences of curricular teachers, with the purpose of creating a close interaction between all of the school professionals (Ministerial Directive, 2012, p. 1). It continues by affirming the necessity of adopting a teaching 
style that would be common for all students in the classroom, so to create an inclusive rather than a special teaching with the support teacher as the main responsible (p. 4). However, such shared interaction among school teachers in relation to SEN students changes already its character in the 2013 Circular, which establishes the competences of the school working group on handicap (GLHI), renamed as the school working group on inclusion (GLI) (Circular no. 8, 2013, p. 4). The GLI monitors the number of SEN students in each school, gathers documents about educational interventions for them, evaluates the level of inclusion of each school and elaborates the school's annual plan for inclusion (PAI). Members of this group, as expressed in the 2013 Circular, should be support teachers, communication assistants, curricular teachers only with specific competences on disability, families, and institutional experts (Circular no. 8, 2013, p. 4, emphasis added). Other curricular teachers might not participate in the elaboration of PAI and might not be interested in promoting inclusion in schools.

The lack of collaboration among all the school professionals, in the effort to promote inclusion, is particularly evident in the ten PAIs analysed here. Ten out of ten PAIs affirm that only members of the working group on inclusion (GLI), that is mostly support teachers, are responsible for the elaboration of the PAI. Ten out of the ten stated the intention of involving general education teachers and other professionals in the making of the document. Furthermore, PAI 1 affirms that support teachers should be deployed mostly in 'individualised activities and integrated workshops and within GLI- GLHI working group' (p. 10). Support teachers should have also 'limited curricular decision making' (p. 11). PAI 2 states the expectation for support teachers to "work in synergy with general education teachers for the realisation of inclusive actions in schools" (p. 14); but how such collaboration should happen is not clear.

A model of inclusion, based on individualised interventions, delegated to the support teachers - perhaps in the corner of the classroom - reproduces microexclusion and stigmatizes migrant students labelled as having SEN. Instead, a DisCrit approach to SEN policy and practices would encourage a collective multimodal analysis that centres multiply marginalised students, creating innovative solutions to injustice, stigma, and labelling for all students (Annamma \& Morrison, 2018).

\section{Disconnection from families and communities}

Parents and members of the community of all students, particularly migrant students labelled with SEN, are described as 'helpers' instead of partners and allies in the learning process in SEN policies at national and local level. All of the PAIs considered in the study affirm the intention to involve families in inclusive activities, projects, and the very own PAI elaboration. Consequently, the active involvement of parents and members of the communities is not a practice that exists already in 'inclusive' Italian schools. While nine of the PAIs stated the importance of considering families in the making of the PAI, which implies that family are not actively involved in the PAI, only PAI 2 explicitly affirmed that 'families have no decision-making power in the elaboration of the PAI' (p. 14).

Such distance between school professionals, families, and communities is particularly damaging for a school environment which promotes itself as being inclusive. The dominant, white, Italian, heteronormative perspective of behaviour, disability, and diversity is reproduced and not challenged and, as a consequence, 
multiply-marginalised students and their community lose their trust in teachers and educational institutions. A DisCrit approach to SEN policies and practice in the Italian context would help to build relationships rooted in solidarity, love, and care between teachers and students and between teachers and families. DisCrit locates students' actions, and those of their families and communities as strategies of resistance and mechanisms to uphold their truth(s) as authentic (Annamma \& Morrison, 2018).

\section{Discussion}

Amidst the increase in migration influx into Southern Europe, and the significant number of migrant and forced migrant students in mainstream classrooms, this paper has explored the discrepancies and criticalities of SEN policies in Italy. It investigates the extent to which such policies support equity and inclusion for all students particularly those from migrant backgrounds. Drawing on DisCrit as an intersectional critical framework (see Annamma, Connor, Ferri, 2013; 2016), this paper highlights how SEN policies in Italy are actually oriented to the identification, classification and categorisation of difference within mainstream school settings. As a result, these policies legitimate the disproportionality of migrant students in the macro-category of Special Educational Needs.

Applying the critical intersectional framework of Disability Critical Race Theory in Education in the Italian context has provided insights into the ways that disability serves as an instrument of institutionalised systems of disadvantage for migrant students, largely because of definitional assumptions associated with the technicalrational understanding of disability. It is hoped that the paper also contributes to the international educational research and, more generally, to Disability Critical Race Theory by showing how the 'special needs' and individual 'deficit' rhetoric continue to dominate the educational policy discourse despite the existence of a radical desegregation policy.

\section{Implications}

We believe that a deliberate commitment to analysing inclusion and SEN policies in Italy through the DisCrit framework would address much of the racism, ableism, and intersecting oppressions that are reiterated in such policies and in everyday classroom practice. Reflecting and modifying these policies through DisCrit can directly impact the achievement, behaviour and disability labelling of migrant students, and indeed all students. Moreover, DisCrit would align with the Disability Studies perspective in Italy in the objective to impact disproportionately negative outcomes. Without explicit commitment to address the interdependence of racism and ableism, and intersecting oppressions (Annamma, Connor \& Ferri, 2016), we believe that there will be a continuation of race-neutral policies and practices.

A DisCrit approach to SEN policies and practices will guide teachers in understanding how multiple marginalisations push students out of schools, and lead parents to not trust educational institutions. The ultimate goal of DisCrit is to 'gather, preserve and grow' the future of migrant students, marginalised students and all students. 


\section{Notes}

${ }^{1} 2012$ Ministerial Directive, Strumenti d'Intervento per Alunni con Bisogni Educativi Speciali e Organizzazione Territoriale per l'Inclusione Scolastica. [Available at: http://www.marche.istruzione.it/dsa/allegati/dir271212.pdf ]; 2013 Circular n ${ }^{\circ}$, Strumenti d'Intervento per gli Alunni con i Bisogni Educativi Speciali, [Available at: http://www.flcgil.it/legginormative/documenti/circolari-ministeriali/circolare-ministeriale-8-del-6-marzo-2013-strumenti-diintervento-per-gli-alunni-con-bisogni-educativi-speciali-bes.flc].

${ }^{2}$ Law 118/1971; Framework Law n. 104/1992.

${ }^{3}$ The 7 tenets of DisCrit are: Tenet 1: DisCrit focuses on ways that the forces of racism and ableism circulate interdependently, often in neutralised ways to uphold notions of normalcy. Tenet 2: DisCrit values multidimensional identities and troubles singular notions of identity such as race or dis/ability, or class or gender or sexuality. Tenet 3: DisCrit emphasises the social constructions of race and ability and yet recognises the material and psychological impacts of being labelled as raced or dis/abled, which sets one outside of the western cultural norms. Tenet 4: DisCrit privileges voices of marginalised populations, traditionally not acknowledged within research. Tenet 5: DisCrit considers legal and historical aspects of dis/ability and race and how both have been used separately and together to deny the rights of some citizens. Tenet 6: DisCrit recognises whiteness and Ability as Property, and that gains for people labelled with dis/abilities have largely been made as the result of interest convergence of White, middle-class citizens. Tenet 7: DisCrit requires activism and supports all forms of resistance (Annamma et al., 2013, 2016).

${ }^{4}$ For a reference to the elitist character of Italian citizenship, refer to Paynter, E. (2017). 'The space of citizenship: mapping personal and colonial histories in contemporary Italy in Igiaba Scego's La mia casa è dove sono (my home is where I am). European Journal of Life Writing, 6. 


\section{References}

Allen, R. L. (2002). The globalization of white supremacy: Toward a critical discourse on the racialization of the world. Educational Theory, 51(4), 467-485.

Annamma, S. A. (2018). The pedagogy of pathologization. Dis/abled girls of color in the school-prison nexus. New York: Routledge.

Annamma, S., \& Morrison, D. (2018). DisCrit classroom ecology: Using praxis to dismantle dysfunctional education ecologies. Teaching and Teacher Education, 73, 70-80.

Annamma, S. A., Connor, D., Ferri, B. (2013). Dis/ability critical race studies (DisCrit): Theorizing at the intersections of race and dis/ability. Race Ethnicity and Education, 16(1), 1-31.

Annamma, S.A., Connor, D., \& Ferri, B. (Eds). (2016). DisCrit. Disability studies and critical race theory in education. New York, NY: Teachers College Press.

Archer, M. S. (1988). Culture and agency. Cambridge: Cambridge University Press.

Artiles, A. J. (2011). Towards an interdisciplinary understanding of equity and difference: The case of the racialization of ability. Educational Researcher, 40(9), 431-445.

Artiles, A. J. (2013). Untangling the racialization of disabilities. Du Bois Review: Social Science Research on Race, 10(2), 329-347.

Artiles, A. J., Rueda, R., Salazar, J. J., \& Higareda, I. (2005). Within-group diversity in minority disproportionate representation: English language learners in urban school districts. Exceptional Children, Vol. 71, 3, pp. 283-300.

Ball, S., Maguire, M., \& Braun, A., (2012). How schools do policy. Policy enactments in secondary schools. London and New York: Routledge.

Bell, C. (2006). Introducing White Disability Studies: A modest proposal. The Disability Studies Reader, Second Edition. New York: Routledge, pp. 275-282.

Beratan, G. (2008). The song remains the same: The disproportionate representation of minority students in special education. Race, Ethnicity and Education, 11(4), 337-354.

Berhanu, G., \& Dyson, A. (2012). Special education in Europe, over-representation of minority students. In J. Banks (Ed.), Encyclopedia of diversity in education (pp. 2070-2073). Thousand Oaks: SAGE Publications.

Brantlinger, E. (Ed.). (2008). Who benefits from special education? New York: Routledge.

Caldin, R. (Ed.). (2012) Alunni con Disabilità, Figli di Migranti. Approcci culturali, questioni educative, prospettive inclusive. [Students with Disabilities, Children of Migrant Families. Cultural approaches, educational issues, inclusive perspectives] Napoli: Liguori Editore.

Canevaro, A. (2001). L'Integrazione in Italia. In S. Nocera (Ed.), Il Diritto all'Integrazione nella Scuola dell'Autonomia. Gli alunni in situazione di handicap nella normativa italiana [The Right to Integration in the School of Autonomy. Pupils with disabilities in Italian legislation] (pp. 209223). Trento: Erickson.

Circular no. 8. (2013). Strumenti d'Intervento per gli Alunni con i Bisogni Educativi Speciali. [Intervention Tools for Students with Special Educational Needs] Available at: http://www.flcgil.it/leggi-normative/documenti/circolari-ministeriali/circolare-ministeriale-8-del6-marzo-2013-strumenti-di-intervento-per-gli-alunni-con-bisogni-educativi-speciali-bes.flc

Crenshaw, Kimberle (1989). Demarginalizing the Intersection of Race and Sex: A Black Feminist Critique of Antidiscrimination Doctrine, Feminist Theory and Antiracist Politics. University of Chicago Legal Forum: Vol. 1989, Article 8, pp. 139-167. Available at: https://chicagounbound.uchicago.edu/uclf/vol1989/iss1/8

Crossley, M. (1999). The disability kaleidoscope. Notre Dame Law Review, 74(3), 621-716. 
D’Alessio, S., Watkins, A., Donnelly, V. (2010). Inclusive education across Europe: The move in thinking from integration to inclusion. Revista de Psicología y Educación Madrid, 1(5), 109-127.

D’Alessio, S. (2011). Inclusive education in Italy. A critical analysis of the policy of integrazione scolastica. Sense Publishers: Rotterdam.

D'Alessio, S. \& Cowan, S. (2013). Cross-cultural approaches to the study of 'inclusive education' and 'special needs' education'. Annual Review of Comparative and International Education in International Perspectives on Education and Society (IPES) Series, 23, 227-261.

D’Alessio, (2014). Le normative sui bisogni educativi speciali in Europa e in Italia. Verso un'educazione inclusiva? La prospettiva dei Disability Studies. [The regulations on special educational needs in Europe and in Italy. Towards an inclusive education? The perspective of Disability Studies]. In P. Gaspari (Ed.), Pedagogia speciale e BES (pp. 217-244). Anicia: Roma.

D’Alessio, S. (2018). Inclusion in Italy: How supposedly inclusive policies fail. National Inclusive Education Month, Inclusive Education Canada. Retrievable online at: http://inclusiveeducation.ca/2018/03/13/inclusion-in-italy-how-supposedly-inclusive-policies-fail/

Drilik, A. (1999). Formations of globality and radical politics. The Review of Education/Pedagogy/ Cultural Studies, 21, 4, 301-338.

Dyson, A., \& Gallannaugh, F. (2008). Disproportionality in special needs education in England. Journal of Special Education, 42(1), 36-46.

Dyson, A., \& Kozleski, E. (2008). Disproportionality in special education: A transatlantic phenomenon. In L. Florian, \& M. McLaughlin (Eds.), Disability classification in education: Issues and perspectives (pp. 170-190). Thousand Oaks: Corwin Press.

Eisenhardt, K. M. (1989). Building theories from case study research. The Academy of Management Review, 14(4), 532-550.

Erevelles, N., \& Minear, A. (2010). Unspeakable offences: Untangling race and disability in discourses of intersectionality. Journal of Literary \& Cultural Disability Studies, 4(2), 127-145.

European Agency for Development in Special Needs Education (2010). SEN Data Collection, Odense.

European Union (2012). Education and disability/special needs, NESSE Report. Bruxelles. Available at: http://www.nesse.fr/nesse/activities/reports/activities/reports/disability-special-needs

Fairclough, N. (2010). Critical discourse analysis: The critical study of language. Harlow: Pearson Education Limited.

Ferri, B. (2008). Inclusion in Italy: What happens when everyone belongs. In B. Ferri (Ed.), Disability and the politics of education: An international reader (pp. 41-52). New York: Peter Lang Publishing.

Gabel, S. L., Curcic, S., Powell, J. J. W., Khader, K., \& Albee, L. (2009). Migration and ethnic group disproportionality in special education: An exploratory study. Disability and Society, 24(5), 625639.

Harry, B., \& Klingner, J. (2014). Why are so many minority students in special education? (2nd ed.). New York: Teachers College Press.

Kivirauma, J., Klemala, K., \& Rinne, R. (2006). Segregation, integration, inclusion. The ideology and reality in Finland. European Journal of Special Needs Education, 21(2), 117-133.

Medeghini R. (2013). Formazione sui Bisogni Educativi Speciali. [Training on Special Educational Needs] Ufficio Scolastico Regionale di Mantova, Mantova, Italy. Available online: http://www.istruzione.lombardia.gov.it/mantova/formazione-sui-bes-col-prof-roberto-medeghini/ Medeghini R., \& Valtellina E. (2006). Quale disabilità? [Which disability?] FrancoAngeli: Milano. 
Migliarini, V. (2017). Intersectionality and the education of dis/abled asylum-seeking and refugee children in Rome: Criticism and discrepancies of 'integration-style inclusion' models. Unpublished Doctoral dissertation.

Migliarini, V. (2018). 'Colour-evasiveness' and racism without race: The disablement of asylumseeking children at the edge of fortress Europe. Race, Ethnicity and Education, 21(4), 438-457.

Ministerial Directive (2012). Strumenti d'Intervento per Alunni con Bisogni Educativi Speciali e Organizzazione Territoriale per l'Inclusione Scolastica. [Intervention Tools for Students with Special Educational Needs and Territorial Organization for School Inclusion]. Available at: http://www.marche.istruzione.it/dsa/allegati/dir271212.pdf

Ministero del Lavoro e delle Politiche Sociali (2015). I Minori Stranieri non Accompagnati (MSNA) in Italia: Report di monitoraggio. [Non Accompanied Foreign Minors (MSNA) in Italy: Monitoring Report]. Available online at: http://www.lavoro.gov.it/notizie/Documents/Repor-di-monitoraggio31-dicembre-2015.pdf

Papastephanou, M. (2005). Globalisation, globalism and cosmopolitanism as an educational ideal. Educational Philosophy and Theory, 37(4), 533-551.

Paynter, E. (2017). 'The space of citizenship: mapping personal and colonial histories in contemporary Italy in Igiaba Scego's La mia casa è dove sono. [My home is where I am]. European Journal of Life Writing, 6, pp. 135- 153

Programma Integra (2013). I Minori Stranieri a Roma: Quadro statistico e analisi dei percorsi di integrazione. [The Foreign Minors in Rome: Statistical framework and analysis of integration paths]. Roma: Format Print.

Reid, K. D., \& Knight, M. G. (2006). Disability justifies exclusion of minority students: A critical history grounded in disability studies. Educational Researcher, 35(6), 18-23.

Tomlinson, S. (2017). A sociology of special and inclusive education: Exploring the manufacturing of inability. New York: Routledge.

UNESCO (1994). The Salamanca Statement and Framework for Action on Special Needs Education,

Salamanca.

UNESCO (2003). Open file on inclusive education. France: UNESCO.

Van Dijk, T. A. (1993). Elite discourse and racism. London: Sage.

Watermeyer, B. (2013). Towards a contextual psychology of disablism. New York: Routledge.

Wiley, A. L., Brigham, F. J., Kauffman, J. M., \& Bogan, J. E. (2013). Disproportionate poverty, conservatism, and the disproportionate identification of minority students with emotional and behavioral disorders. Education and Treatment of Children, 36(4), 29-50. 